\title{
Enhanced wear and corrosion resistance of plasma electrolytic carburized layer on T8 carbon steel
}

\author{
Jie Wu ${ }^{\text {a, b }}$, Bin Wang ${ }^{\text {a, b }}$, Yifan Zhang ${ }^{\text {a, b }}$, Run Liu ${ }^{\text {a, b }}$, Yuan Xia ${ }^{c}$, Guang Li $^{c}$, \\ Wenbin Xue ${ }^{\text {a, b, * }}$ \\ a Key Laboratory for Beam Technology and Materials Modification of Ministry of Education, College of Nuclear Science and Technology, Beijing Normal \\ University, Beijing 100875, China \\ ${ }^{\mathrm{b}}$ Beijing Radiation Center, Beijing 100875, China \\ c Institute of Mechanics, Chinese Academy of Sciences, Beijing 100190, China
}

\section{H I G H L I G H T S}

- Electron temperature in plasma electrolytic carburizing process is determined.

- Diffusion coefficient of carbon in PEC is higher than conventional carburizing.

- Wear and corrosion resistance of T8 steel are both improved after PEC treatment.

- Pitting corrosion of steel substrate is obviously suppressed by PEC treatment.

\section{A R T I C L E I N F O}

\section{Article history:}

Received 6 November 2014

Received in revised form

6 September 2015

Accepted 29 September 2015

Available online 21 December 2015

\section{Keywords:}

Arc discharges

Surface properties

Wear

Corrosion

\begin{abstract}
A B S T R A C T
A hardening layer of $70 \mu \mathrm{m}$ on T8 carbon steel was fabricated by plasma electrolytic carburizing (PEC) in glycerol solution at $380 \mathrm{~V}$ with 3 min treatment. The discharge process was characterized using optical emission spectroscopy (OES), and the electron temperature in plasma envelope was determined. Meanwhile, diffusion coefficient of carbon was calculated on the basis of carbon concentration profile. The tribological property of carburized steel under dry sliding against $\mathrm{ZrO}_{2}$ ball was measured by a balldisc friction and wear tester. The corrosion behaviors were evaluated by potentiodynamic polarization and electrochemical impedance spectroscopy (EIS). It was found that the carburized layer mainly contained $\alpha-\mathrm{Fe}$ and $\mathrm{Fe}_{3} \mathrm{C}$ phases with maximum hardness of $620 \mathrm{HV}$. The PEC treatment significantly decreased the friction coefficient from 0.4 to 0.1. The wear rate of PEC treated steel was about $5.86 \times 10^{-6} \mathrm{~mm}^{3} / \mathrm{N} \cdot \mathrm{m}$, which was less than $1 / 4$ of T8 steel substrate. After PEC treatment, the wear and corrosion resistance of T8 steel were improved. Particularly, the pitting corrosion of steel substrate was obviously suppressed.
\end{abstract}

() 2015 Elsevier B.V. All rights reserved.

\section{Introduction}

Chemical heat treatment methods such as carburizing, nitriding and carbonitriding have been developed to improve the surface hardness of steel materials. T8 high carbon steel, as a kind of carbon tool steel is widely used in the mould making due to its better processability and lower price. But conventional heat treatment

\footnotetext{
* Corresponding author. Key Laboratory for Beam Technology and Materials Modification of Ministry of Education, College of Nuclear Science and Technology, Beijing Normal University, Beijing 100875, China.

E-mail address: xuewb@bnu.edu.cn (W. Xue).
}

including the pack carburizing and gas carburizing always leads to a large distortion of work pieces. Moreover, these methods usually carry out at high temperature up to $1000{ }^{\circ} \mathrm{C}$ or proceed in the vacuum environment, which results in high energy consumption and high cost [1-5]. In recent years, plasma electrolytic saturation (PES) technology has been studied as an efficient and environmentally friendly approach for surface hardening on metals [6]. Specific processing methods include plasma electrolytic carburizing (PEC), plasma electrolytic carbonitriding ( $\mathrm{PEC} / \mathrm{N})$, plasma electrolytic borocarburizing (PEB/C) [7-9] and so on.

In the PES process, the work piece as cathode is immersed in organic electrolyte solution at ambient temperature. When the negative bias voltage is applied, the electrolyte solution is heated to 
produce a continuous vapor envelope around the steel sample. By increasing the applied voltage to a critical value, the vapor envelope is broken down, resulting in plasma discharge at near-cathode region and an enhanced interstitial diffusion of active species like carbon, nitrogen and boron. Li et al. [10] successfully prepared a $\mathrm{Ti}\left(\mathrm{C}_{\mathrm{x}} \mathrm{N}_{1-\mathrm{x}}\right)$ film on titanium by PEC/N method in a mixed organic solution of triethanolamine and formamide. The film showed a good adhesion and high hardness. Tarakci et al. [11] produced a carburized layer on pure iron by PEC method. The hardness of the carbon-rich layer was significantly improved compared with the pure iron substrate. On this basis, Çavuşlu et al. [12] measured the wear rates of untreated and PEC treated pure iron. It showed that the carburized pure iron samples had lower wear rate and better wear resistance. However, the corrosion behavior of the PEC layer has not been evaluated. On the other hand, P. Belkin et al. [13] reported an anodic PEC treatment on carbon steel. There was a thick oxide layer covered on the carburized layer, but the carbon concentration was only 0.8 wt.\% and the evaluation of layer performance was insufficient. So it is meaningful to examine the PEC layer properties combining wear and corrosion resistance.

In this paper, a carburized layer on T8 high carbon steel was rapidly fabricated by PEC method in an aqueous glycerol solution. Optical emission spectroscopy was employed to characterize the discharge phenomenon during PEC process. The microstructure, phase constituents and hardness profile of PEC treated steel were analyzed. The tribological behavior under dry sliding at ambient temperature and electrochemical performance were investigated. Besides, the carburization mechanism in PEC process was discussed.

\section{Material and methods}

A T8 high carbon steel (C: $0.75-0.84, \mathrm{Si}: \leq 0.35, \mathrm{Mn}: \leq 0.40, \mathrm{P}$ : $\leq 0.035$, S: $\leq 0.030$, wt.\%, Fe balance) plate with dimensions of $55 \mathrm{~mm} \times 16 \mathrm{~mm} \times 1 \mathrm{~mm}$ was used as substrate material. The plate was mechanically polished with 1000-grit emery paper, and then was cleaned in ethanol and dried. For the PEC treatment, a DC power supply was employed, and the T8 steel plate was used as cathode while a stainless steel container served as anode. The aqueous solution containing 80 vol.\% glycerol was chosen as electrolyte. The negative bias voltage was initially set at $150 \mathrm{~V}$ to produce a continuous vapor envelope around the T8 sample. Then the applied voltage gradually increased and the vapor envelope was broken down at the critical voltage. When the voltage reached $380 \mathrm{~V}$, the plasma discharge became stable. After 3 min treatment, the power supply was turned off slowly [14], and the T8 steel sample was cleaned in running water and dried.

During stable discharge, the active species in the plasma envelope were detected using optical emission spectroscopy (OES, AvaSpec-3648). The surface morphology and cross-sectional microstructure of PEC treated steel were observed by scanning electron microscope equipped with energy dispersive spectroscopy (SEM \& EDS, Hitachi S-4800). A Vicker's microhardness tester with $10 \mathrm{~g}$ load was used to determine the hardness profile of PEC sample. The phase constituents of the sample before and after carburization were characterized by X-ray diffraction (XRD, X'Pert Pro MPD). A ball-disc friction and wear tester was employed to measure the tribological properties. The wear test was carried out under dry sliding with $5 \mathrm{~N}$ load against $\mathrm{ZrO}_{2}$ ball of $4.763 \mathrm{~mm}$ in diameter. The surface roughness of samples and the cross-sectional profiles of wear tracks were measured by a surface profilometer equipped with a diamond stylus (TR200, Beijing Time Lianchuang technology Co., Ltd). Corrosion behaviors of PEC sample before and after polishing were evaluated using electrochemical workstation (PARSTAT 2273) in 3.5 wt.\% $\mathrm{NaCl}$ aqueous solution. Potentiodynamic polarization tests were performed at a scan rate of $1 \mathrm{mV} / \mathrm{s}$. Electrochemical impedance spectroscopy (EIS) was carried out at the open circuit potential with an AC amplitude of $10 \mathrm{mV}$ over the frequency range of $1 \mathrm{MHz}$ to $0.01 \mathrm{~Hz}$. A polishing machine with metallographic polishing cloth was employed to remove the residual carbon particles on the PEC specimen surface. The rotational speed of the polishing machine is $600 \mathrm{r} / \mathrm{min}$. The surface roughness of the polished PEC specimen is $0.39 \mu \mathrm{m}$.

\section{Results and discussion}

\subsection{Spectroscopic investigation of plasma discharge}

According to the theory of atomic emission spectrum, during the transition of excited atoms from higher level to lower level, the energy will be released in the form of light radiation to generate OES spectrum. Fig. 1 shows a typical OES spectrum of the plasma discharge on T8 steel in glycerol aqueous solution. The plasma zone contains iron from steel substrate, and carbon, hydrogen, oxygen from electrolyte. Meanwhile, there are no strong signals below $350 \mathrm{~nm}$ wavelength, probably due to the self-absorption of light [15]. The H I refers to a neutral hydrogen atom, while the C II, Fe II and $\mathrm{O}$ II are singly ionized atoms. The emission intensity of active species can be utilized to indicate whether the plasma has produced the operation conditions required for a certain coating process. As far as this experiment is concerned, active Fe, H, O, C radicals and ionic components take part in the discharge reaction to fabricate a carburized layer on T8 steel, and carbon species are dominant during this process.

On the other hand, the plasma produced during PEC process belongs to a local thermal equilibrium (LTE) plasma. In the LTE state, the electron temperature $\left(T_{\mathrm{e}}\right)$ can be obtained from Eq. (1) when relative line intensities of the same atomic or ionic species are given [16].

$\frac{I_{1}}{I_{2}}=\frac{A_{1} g_{1} \lambda_{2}}{A_{2} g_{2} \lambda_{1}} \exp \left(-\frac{E_{1}-E_{2}}{k T_{e}}\right)$

where $I_{1}, A_{1}, g_{1}, \lambda_{1}, E_{1}$ and $I_{2}, A_{2}, g_{2}, \lambda_{2}, E_{2}$ are relative intensity, transition probability, statistical weight of upper level, wavelength and excitation energy of the two emission spectral line, respectively, and $k$ is the Boltzmann constant. Combined with the spectrum in Fig. 1, the Fe II lines at $516.65 \mathrm{~nm}$ and $697.57 \mathrm{~nm}$ are selected to determine the $T_{\mathrm{e}}$. Corresponding parameters are listed in Table 1

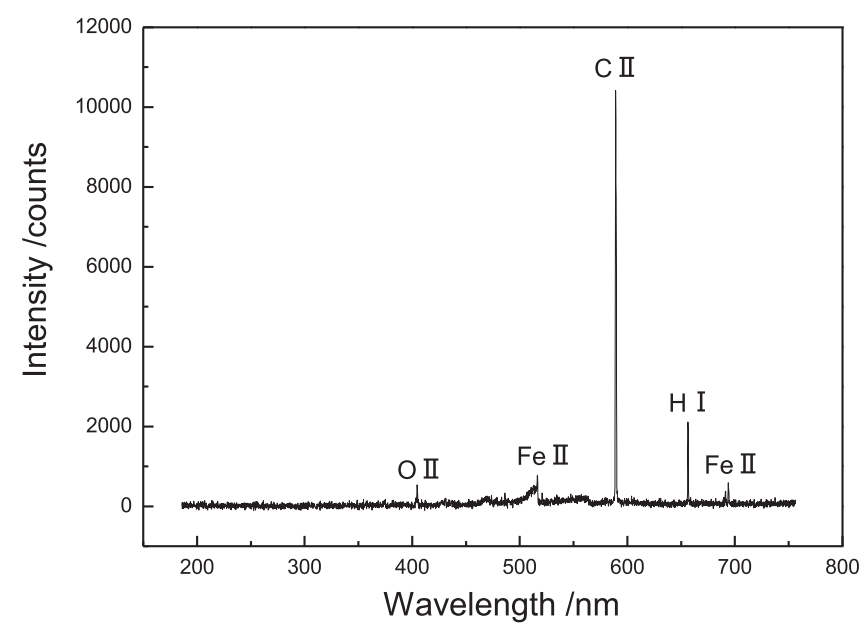

Fig. 1. Typical emission spectrum of PEC process on T8 steel in glycerol aqueous solution. 
Table 1

Fe II lines with the wavelength, transition, statistical weights of upper level, energy difference between the two levels and transition probabilities.

\begin{tabular}{llllll}
\hline Line & $\lambda(\mathrm{nm})$ & Transition & $g_{\mathrm{k}}$ & Energy $(\mathrm{eV})$ & $A_{\mathrm{ki}}\left(10^{7} \mathrm{~S}^{-1}\right)$ \\
\hline Fe II & 516.65 & $3 \mathrm{~d}^{6}\left({ }^{5} \mathrm{D}_{2}\right) 4 \mathrm{f} \rightarrow 3 \mathrm{~d}^{6}\left({ }^{5} \mathrm{D}\right) 4 \mathrm{~d}$ & 8 & 2.4 & 2.82 \\
Fe II & 697.57 & $3 \mathrm{~d}^{6}(5 \mathrm{D}) 5 \mathrm{~d} \rightarrow 3 \mathrm{~d}^{6}\left({ }^{5} \mathrm{D}\right) 5 \mathrm{p}$ & 4 & 1.8 & 1.92 \\
\hline
\end{tabular}

[17]. The calculated $T_{\mathrm{e}}$ is about $5000 \mathrm{~K}$, which refers to a transient temperature of plasma discharge zone.

\subsection{Morphology and microstructure of carburized layer}

Fig. 2a is the surface micrograph of PEC treated steel with 3 min discharge. Some remained cavities and channels on the surface can be observed, which result from intense plasma etching during discharge process. Furthermore, the surface roughness of PEC treated steel becomes $0.56 \mu \mathrm{m}$ while the steel substrate is only $0.18 \mu \mathrm{m}$. The EDS map of the surface is displayed in Fig. 2b. The C, O, Fe elements are detected on the surface of PEC treated steel. Fig. 3a shows the cross-sectional microstructure of the PEC treated steel. It consists of two layers: a carburized layer of about $30 \mu \mathrm{m}$ and a carbon diffusion layer of about $40 \mu \mathrm{m}$. Active carbon atoms, decomposed from glycerol, permeate into the steel from surface to interior. Since the steel substrate far from the surface keeps relatively low temperature, the carbon diffusion is gradually suppressed and the carbon atoms accumulate in some regions. Then the residual carbon atoms diffuse along the grain boundary to form the diffusion layer due to the irregular atomic arrangement and
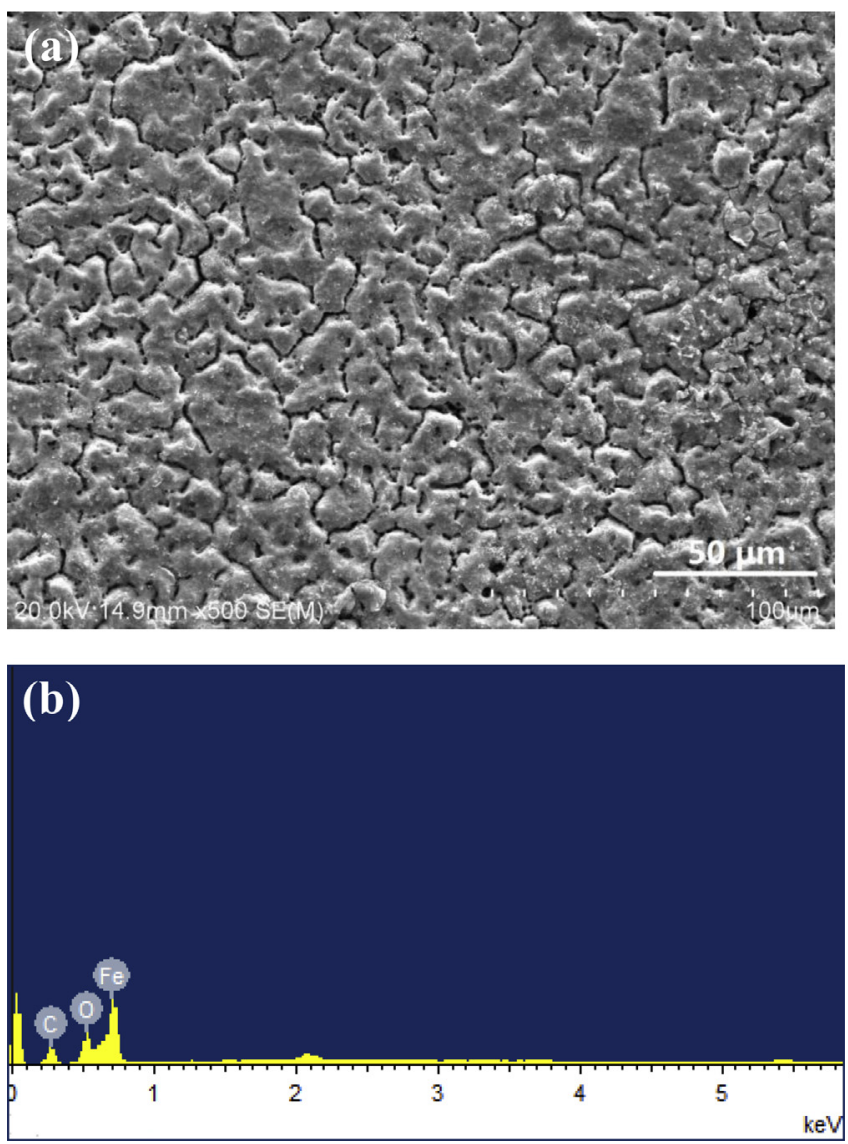

Fig. 2. (a) Surface morphology of the PEC treated steel with 3 min treatment. (b) Typical EDS map of the steel surface after PEC treatment.
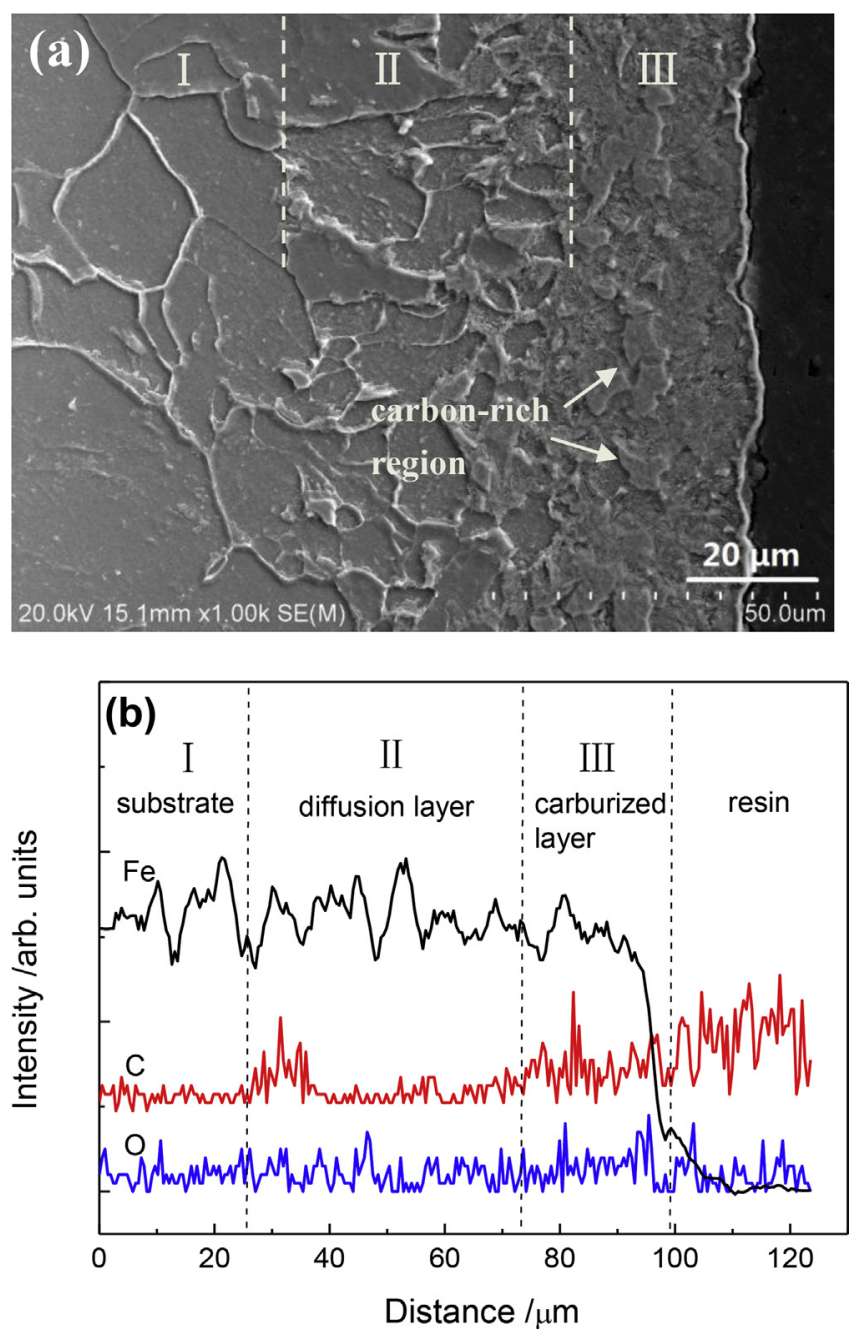

Fig. 3. (a) Cross-sectional microstructure of the PEC treated steel: I substrate, II diffusion layer, III carburized layer. (b) Composition distribution of Fe, C and $\mathrm{O}$ elements in the PEC treated steel.

loose structure in the grain boundary. Fig. 3b displays the composition profiles of Fe, $\mathrm{C}$ and $\mathrm{O}$ elements in the PEC treated steel. The carburized layer and diffusion layer can be distinguished by two carbon peaks. Their thicknesses are consistent with the crosssection image in Fig. 3a. The carbon peaks correspond to the carbon-rich regions, which are formed by carbon atoms accumulation during diffusion process. In addition, iron content decreases in carburized layer while oxygen content slightly increases.

As to Fig. 3a, a one-dimensional diffusion model for the Fick's second law is built and its error function solution is presented as Eq. (2).

$C=C_{S}+\left(C_{0}-C_{S}\right) \operatorname{erf}\left(\frac{x}{2 \sqrt{D t}}\right)$

The notation $C$ refers to the carbon content in position $\mathrm{x}$, while $C_{\mathrm{s}}$ and $C_{0}$ are the carbon content on the surface and in the interior of steel matrix, respectively. $D$ is the diffusion coefficient of carbon atoms. In this simplified model, the steel sample is seen as semiinfinite, and the $C_{s}$ remains unchanged approximately. Fig. 4 shows the distribution of carbon concentration in PEC layer by EDS composition analysis. It is found that the carbon concentration decreases from surface of PEC layer to steel substrate. The peak values originate from the carbon-rich regions in Fig. 3b. In terms of 


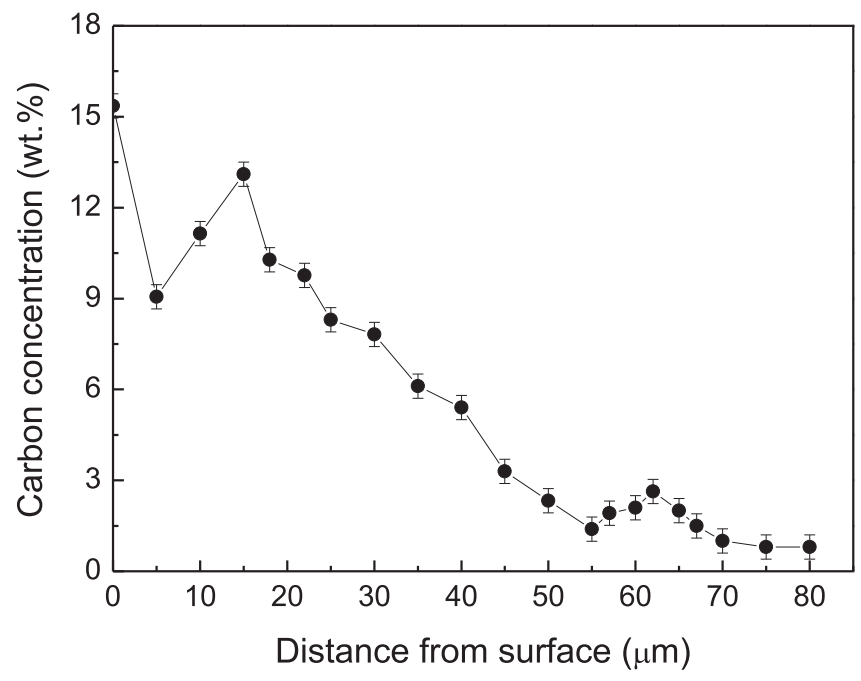

Fig. 4. Carbon concentration profile along the cross section of PEC treated steel.

Eq. (2), the relationship between diffusion distance (x) and carburizing time ( $\mathrm{t}$ ) can be derived, as shown in Eq. (3).

$x=\sqrt{D t}$

In this work, the $\mathrm{x}$ and $\mathrm{t}$ are $70 \mu \mathrm{m}$ and $180 \mathrm{~s}$, respectively. Thus the carbon diffusion coefficient can be calculated, and it turns out to be $2.72 \times 10^{-7} \mathrm{~cm}^{2} \mathrm{~s}^{-1}$. As for the conventional carburizing process, the diffusion coefficient of carbon is determined by carburizing temperature. Eq. (4) depicts the relationship between diffusion coefficient (D) and carburizing temperature (T). The $\mathrm{D}_{0}$ and $\mathrm{Q}$ are constants, given by Ref. [1].

$D=D_{0} \exp \left(-\frac{Q}{R T}\right)$

The carburizing temperature during PEC process is $793.6{ }^{\circ} \mathrm{C}$, which is measured by inserting a thermocouple into the sample. At this temperature, the diffusion coefficient in conventional carburizing process is $1.81 \times 10^{-8} \mathrm{~cm}^{2} \mathrm{~s}^{-1}$, which is one magnitude lower than the diffusion coefficient of PEC process.

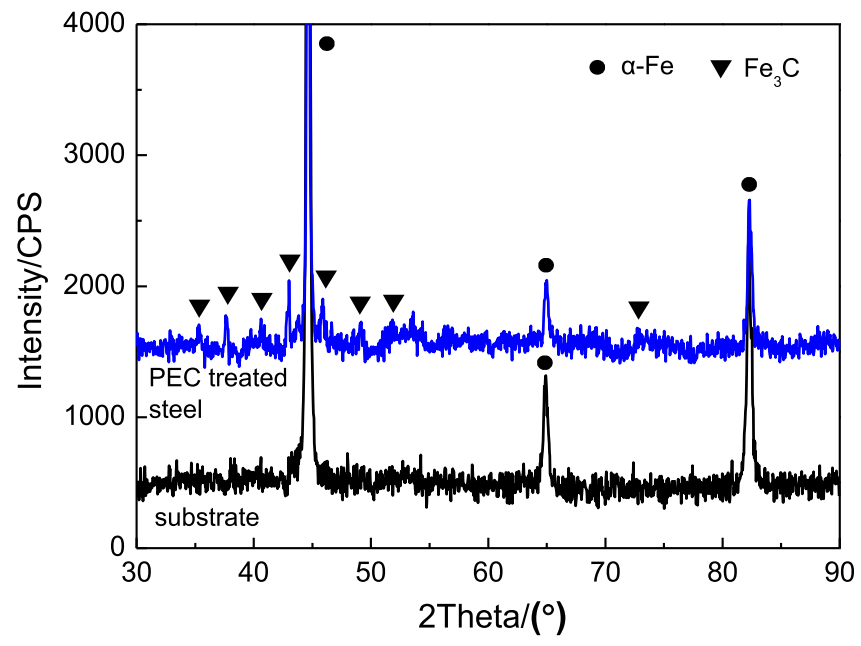

Fig. 5. XRD patterns of bare T8 steel substrate and the PEC treated steel.

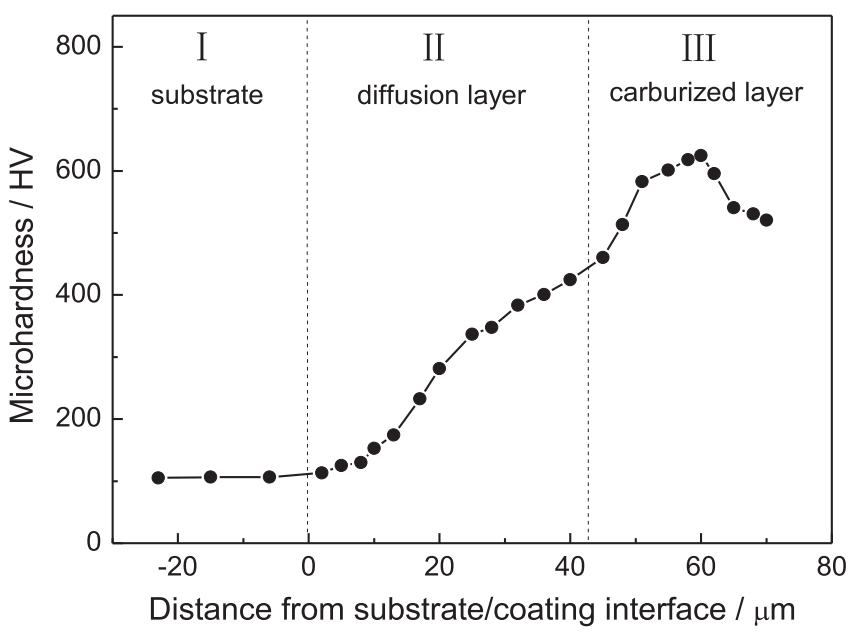

Fig. 6. Microhardness distribution of PEC treated steel across the layer thickness.

3.3. Phase constituents analyses and hardness profile of PEC treated steel

Fig. 5 displays the XRD patterns of T8 steel before and after PEC treatment. There is only ferrite $(\alpha-\mathrm{Fe})$ phase in T8 substrate, but in
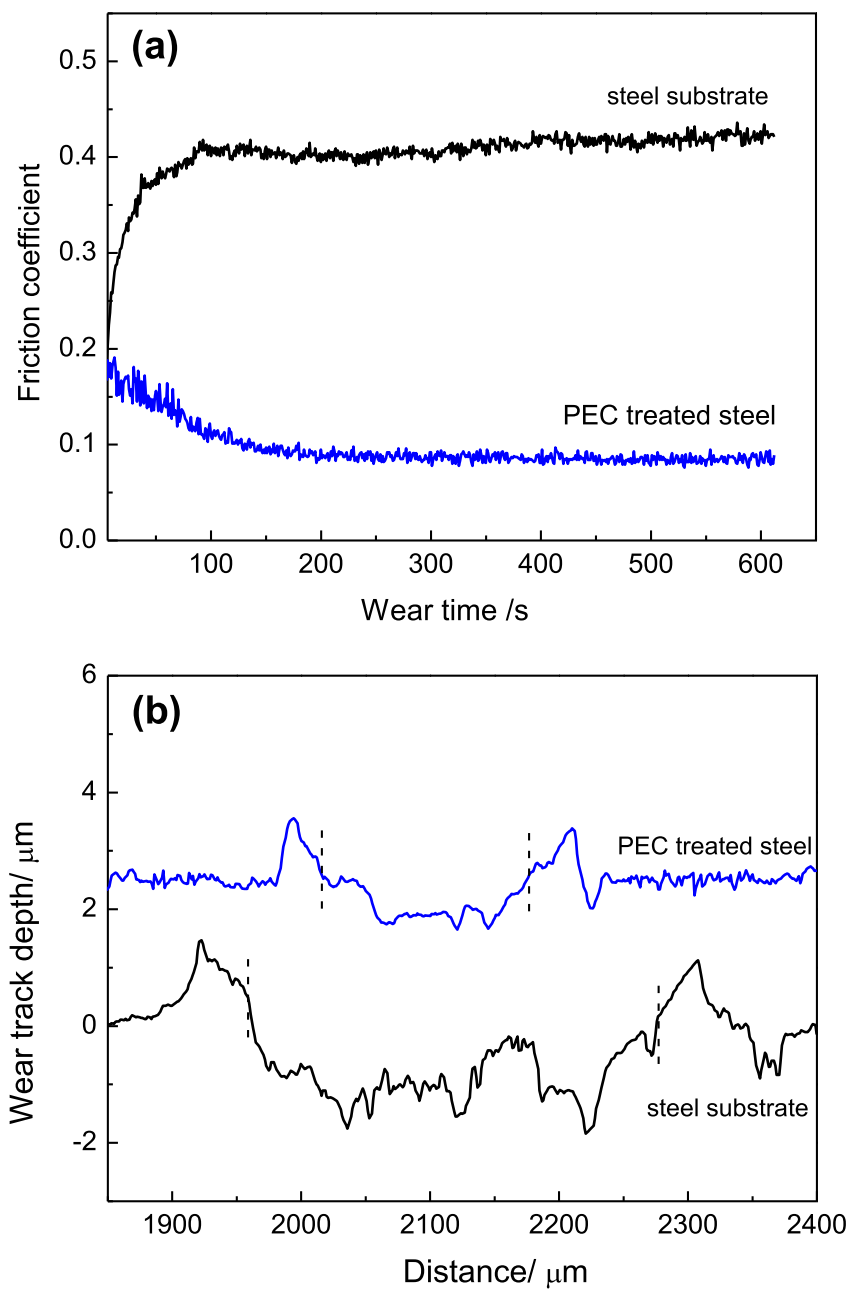

Fig. 7. Friction coefficient (a) and cross-sectional profiles of wear tracks (b) for T8 steel substrate and PEC treated steel against $\mathrm{ZrO}_{2}$ ball with $5 \mathrm{~N}$ load. 
the PEC treated steel some $\mathrm{Fe}_{3} \mathrm{C}$ peaks are detected. The phase constituents of PEC treated steel is similar to that of the conventional gas carburizing technique [18]. It means that the carbon species, decomposed from glycerol through plasma discharge, has diffused into the steel and formed the cementite by precipitating.

The cross-sectional hardness profile of PEC treated steel at $10 \mathrm{~g}$ load is shown in Fig. 6. It is found that the microhardness gradually increases from the steel substrate to the surface of hardening layer. The maximum hardness appears in the carburized layer and corresponds to the carbon accumulated regions or carbon-rich regions in Fig. 3a. The maximum hardness of carburized layer is about $620 \mathrm{HV}$, which is more than five times of the steel substrate (110 HV). It is believed that the high hardness should be ascribed to the appearance of $\mathrm{Fe}_{3} \mathrm{C}$ hard phase as revealed in Fig. 5 .

\subsection{Tribological performance of PEC treated steel}

Fig. 7a depicts the friction coefficient of T8 steel substrate and PEC treated steel under dry sliding against $\mathrm{ZrO}_{2}$ ball with $5 \mathrm{~N}$ load at ambient temperature. At the stable wear stage, the friction coefficient of PEC sample is about 0.1, which is much lower than that of bare steel with about 0.4 . Fig. $7 \mathrm{~b}$ reveals the cross-sectional profiles of wear tracks measured by a surface profilometer. It is clear that the area of wear track for steel substrate is larger than that of PEC treated steel. According to the calculation result, the wear rate of PEC treated steel is about $5.86 \times 10^{-6} \mathrm{~mm}^{3} / \mathrm{N} \mathrm{m}$, which is less than $1 / 4$ of T8 steel substrate. The low friction coefficient and good wear resistance of PEC treated steel are ascribed to the high hardness of carburized layer and the lubrication action of remained carbon particles distributed on the surface.

The surface morphologies of wear tracks on T8 steel substrate and PEC treated steel are shown in Fig. 8a and c. Magnified images are respectively displayed in Fig. 8b and d. Compared with the steel substrate, the wear track of PEC treated steel is narrower, which is consistent with the cross-sectional profiles in Fig. 7b. Furthermore, some parallel grooves and severe peeling can be observed on the substrate surface, suggesting that abrasive wear occurs during the wear test. Besides, the oxygen content of peeled area in Fig. 8b is high. Table 2 shows the compositions of the worn surface of steel substrate and PEC treated steel. The concentrations of $\mathrm{O}$ and $\mathrm{Zr}$ in the dark region $A$ are higher than those in the bright region $B$. Because the friction heat causes local oxidation of the worn surface, and more $\mathrm{Zr}$ element is transferred into dark regions due to longer contact time with $\mathrm{ZrO}_{2}$ ball. In addition, the $\mathrm{O}$ and $\mathrm{Zr}$ contents of PEC treated steel are lower than those of bare steel substrate. This indicates that the oxidation and material transfer for the PEC sample are weaker than those for the bare steel substrate. Meanwhile, the wear track of the PEC treated steel is smooth with some fatigue cracks. The fatigue cracks are pointed out by white arrows in Fig. 8d. The wear mechanism has transformed to oxidation wear and fatigue wear.

\subsection{Corrosion behavior of PEC treated steel}

Fig. 9a shows the polarization curves of T8 steel substrate and PEC treated steel. The corrosion potential $\left(E_{\text {corr }}\right)$, corrosion current density $\left(i_{\text {corr }}\right)$ and polarization resistance $\left(R_{\mathrm{p}}\right)$ are listed in Table 3 . It reveals that both the $E_{\text {corr }}$ and $i_{\text {corr }}$ of PEC treated steel are lower than steel substrate. Thus, the corrosion resistance of PEC treated steel is improved since the polarization curve moves towards the region of lower current density. In addition, after gently polishing the surface of PEC sample, the $i_{\text {corr }}$ decreases slightly from $6.84 \times 10^{-6}$ to $5.72 \times 10^{-6} \mathrm{~A} / \mathrm{cm}^{2}$, while the $E_{\text {corr }}$ increases markedly from -0.5964 to $-0.5065 \mathrm{~V}$. Though the $i_{\text {corr }}$ might be affected
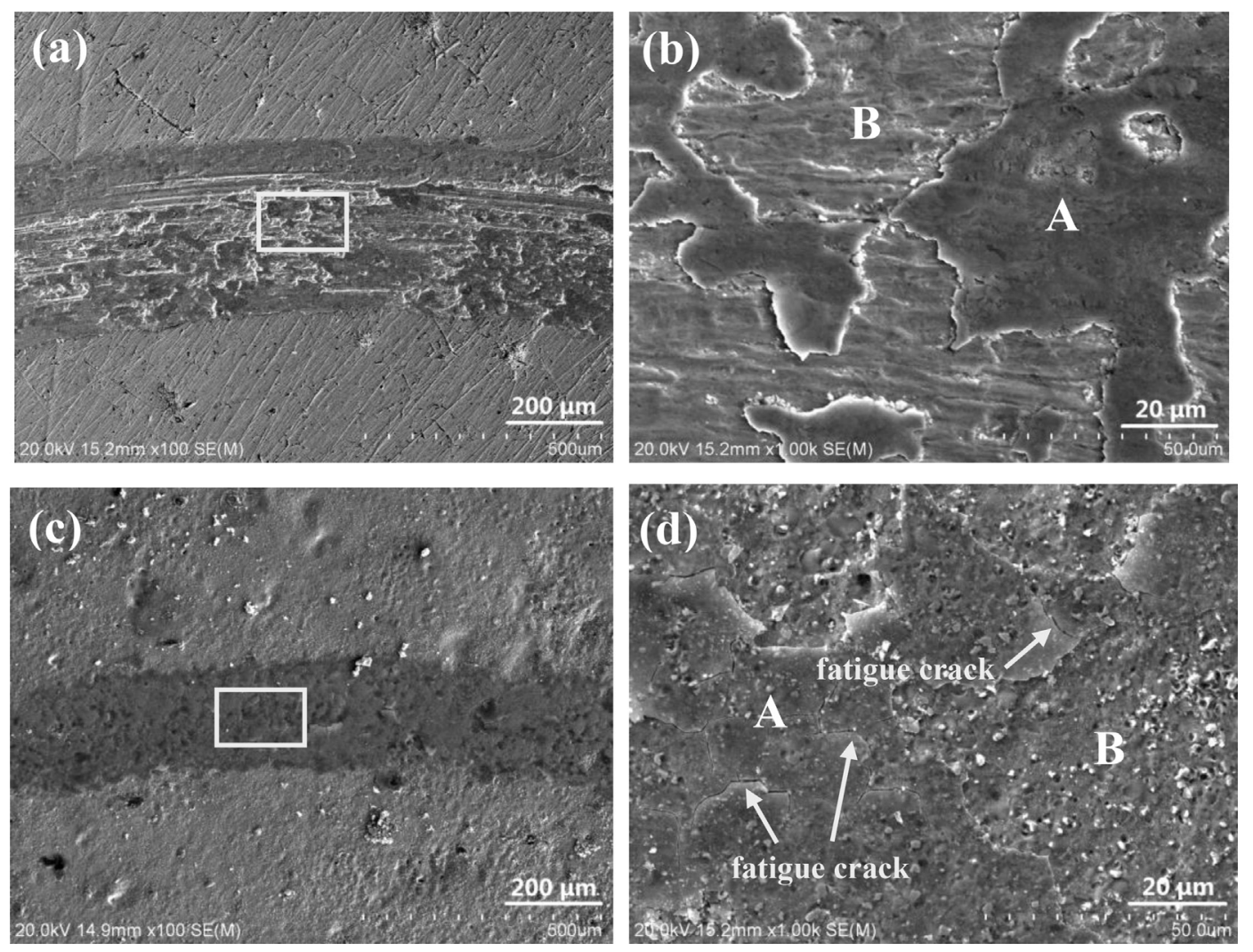

Fig. 8. Morphologies of the wear tracks on T8 steel substrate (a) and PEC treated steel (c); (b) and (d) are the magnification of (a) and (c), respectively. 
Table 2

EDS analyses of the worn surface on steel substrate and PEC treated steel.

\begin{tabular}{|c|c|c|c|c|c|c|}
\hline \multirow[t]{2}{*}{ Weight percentage $\%$} & \multicolumn{2}{|l|}{$\mathrm{O}$} & \multicolumn{2}{|l|}{$\mathrm{Fe}$} & \multicolumn{2}{|l|}{$\mathrm{Zr}$} \\
\hline & Region A & Region B & Region A & Region B & Region A & Region B \\
\hline Steel substrate & 24.37 & 11.13 & 72.84 & 88.87 & 2.79 & 0 \\
\hline PEC treated steel & 10.99 & 4.37 & 88.86 & 95.62 & 0.15 & 0.01 \\
\hline
\end{tabular}

by the reduced surface area of the specimen after polishing, the increase of $E_{\text {corr }}$ implies that the corrosion resistance of the polished PEC steel is improved compared with the unpolished PEC steel. On the other hand, Fig. 9b shows the typical Nyquist plots of steel substrate and PEC treated steel. Their equivalent circuits are proposed in Fig. 9c and d, respectively [19] and the fitting results are listed in Table $4 . R_{\mathrm{S}}$ is solution resistance, $C_{\mathrm{dl}}$ is double layer capacitance, $R_{\mathrm{t}}$ is charge transfer resistance, CPE and $R_{\mathrm{f}}$ are constant phase element and resistance of passive film on steel formed in aqueous solution. $C P E$ is defined as $Z_{C P E}=1 /\left[Y_{0}(j \omega)^{n}\right]$, where $Y_{0}$ is modulus of admittance, $\omega$ is perturbing frequency and $n$ is an exponent to characterize the deviation degree of real capacitance
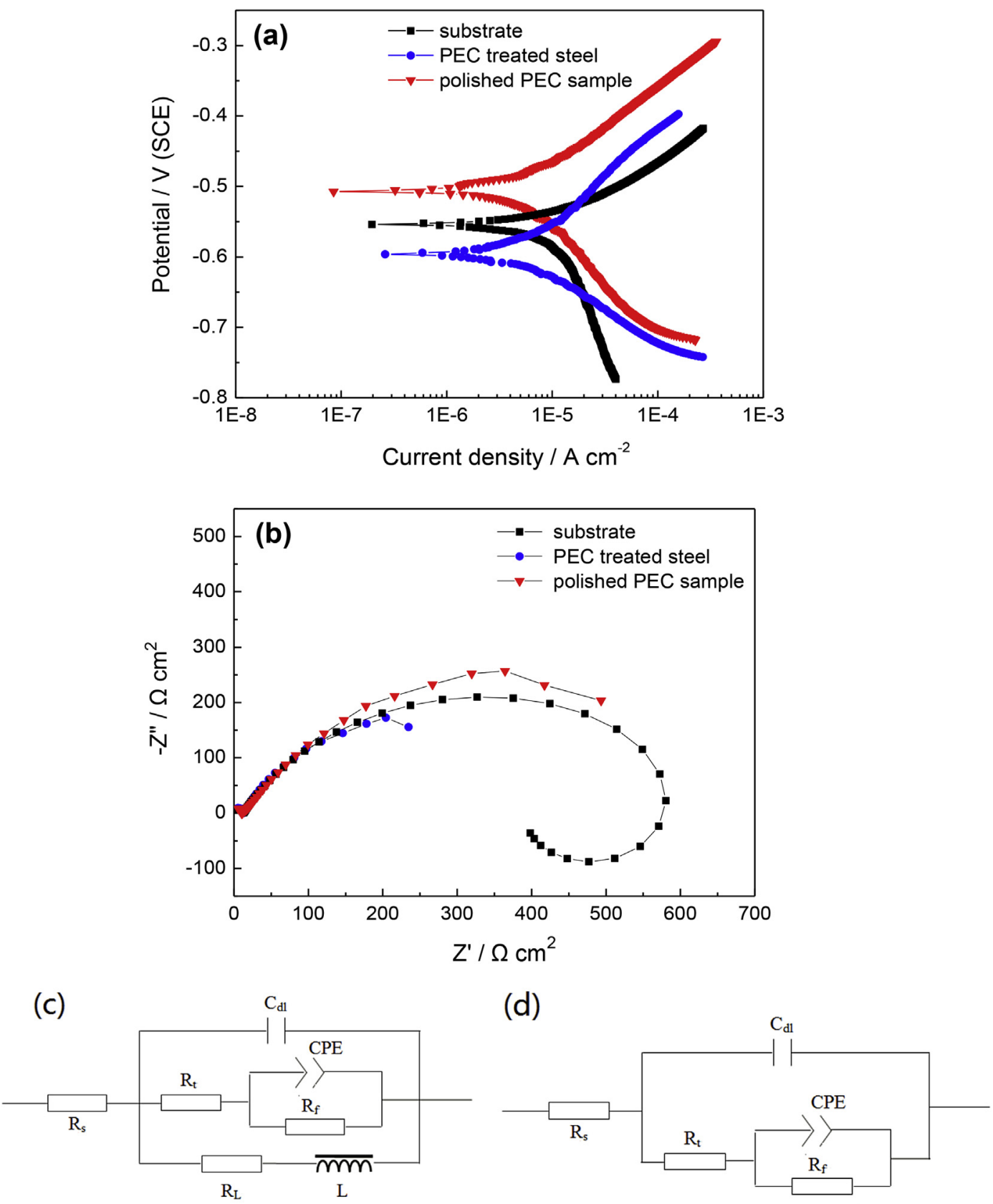

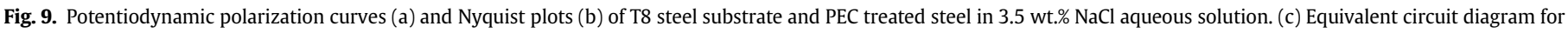
EIS plot of T8 steel substrate. (d) Equivalent circuit diagram for EIS plot of PEC treated steel. 
Table 3

Fitting results of potentiodynamic polarization curves of T8 steel substrate and PEC treated steel before and after polishing.

\begin{tabular}{llll}
\hline & $E_{\text {corr }}(\mathrm{V})$ & $i_{\text {corr }}\left(\mathrm{A} / \mathrm{cm}^{2}\right)$ & $R_{\mathrm{p}}\left(\Omega / \mathrm{cm}^{2}\right)$ \\
\hline Substrate & -0.5554 & $1.19 \times 10^{-5}$ & 2543 \\
PEC treated steel & -0.5964 & $6.84 \times 10^{-6}$ & 4108 \\
Polished PEC sample & -0.5065 & $5.72 \times 10^{-6}$ & 5349 \\
\hline
\end{tabular}

thickness about $30 \mu \mathrm{m}$ on T8 high carbon steel by 3 min discharge treatment at $380 \mathrm{~V}$ in glycerol solution. Below the carburized layer, there is a $40 \mu \mathrm{m}$ thick diffusion layer, which is caused by carbon diffusing along the grain boundary. Diffusion coefficient of carbon atoms into steel during PEC process is calculated to be $2.72 \times 10^{-7} \mathrm{~cm}^{2} \mathrm{~s}^{-1}$, while electron temperature in plasma discharge zone is about $5000 \mathrm{~K}$. The carburized layer mainly con-

Table 4

Fitting results of EIS plots of T8 steel substrate and PEC treated steel before and after polishing.

\begin{tabular}{|c|c|c|c|c|c|c|c|c|}
\hline & $\begin{array}{l}R_{\mathrm{s}} \\
\Omega \mathrm{cm}^{2}\end{array}$ & $\begin{array}{l}C_{\mathrm{dl}} \\
\mathrm{F} \mathrm{cm}^{-2}\end{array}$ & $\begin{array}{l}R_{\mathrm{t}} \\
\Omega \mathrm{cm}^{2}\end{array}$ & $\begin{array}{l}C P E, Y_{0} \\
\Omega^{-1} \mathrm{~cm}^{-2} \mathrm{~s}^{-\mathrm{n}}\end{array}$ & $n$ & $\begin{array}{l}R_{\mathrm{f}} \\
\Omega \mathrm{cm}^{2}\end{array}$ & $\begin{array}{l}R_{\mathrm{L}} \\
\Omega \mathrm{cm}^{2}\end{array}$ & $\begin{array}{l}L \\
\mathrm{H} \mathrm{cm}^{2}\end{array}$ \\
\hline Substrate & 0.01 & $1.562 \times 10^{-8}$ & 12.67 & $5.474 \times 10^{-4}$ & 0.7192 & 589 & 874 & 4251 \\
\hline PEC treated steel & 0.01 & $1.227 \times 10^{-8}$ & 12.78 & $1.783 \times 10^{-2}$ & 0.7476 & 530 & & \\
\hline Polished PEC sample & 0.01 & $1.194 \times 10^{-8}$ & 1.142 & $6.093 \times 10^{-3}$ & 0.6579 & 981 & & \\
\hline
\end{tabular}

from its ideal value $(0<n \leq 1)[20,21] . R_{\mathrm{L}}$ and $L$ are inductance resistance and inductance corresponding to the pitting formation.

The sensitivity of pitting corrosion can be estimated by the EIS plots before the pitting corrosion really occurs. As for the T8 steel substrate, the appearance of inductive loop at low frequency (see Fig. 9b) means that the pitting corrosion is easy to take place on bare steel. After the PEC treatment, the inductive loop in EIS plot does not appear, which implies that the carburized layer can suppress the occurrence of pitting. On the other hand, the capacitive loop diameter of the PEC treated steel is similar to that of T8 steel substrate. After gently polishing the sample surface, the polished PEC sample exhibits a better corrosion resistance compared with the bare steel substrate and the unpolished sample, since the carbon particles have been removed from the surface. The capacitive loop diameter of polished PEC sample is larger and the $R_{\mathrm{f}}$ with $981 \Omega \mathrm{cm}^{2}$ is higher than that of T8 steel substrate. Therefore, the PEC treatment improves the corrosion resistance of steel, which is consistent with the polarization results. Particularly, PEC treatment can suppress the occurrence of pitting corrosion for T8 steel.

Based on the above discussion, the carburization mechanism in PEC process can be summarized as follows. When the applied voltage is initially set at $150 \mathrm{~V}$, the T8 steel surface is heated and a continuous vapor envelope containing hydrogen and glycerol molecules is formed around the steel sample. As the voltage increases, the high voltage mainly concentrates on the thin gas envelope with low electrical conductivity. Then the breakdown of gas envelope occurs at a critical voltage, resulting in the plasma discharge at the near-cathode region. At $380 \mathrm{~V}$, the plasma discharge becomes stable and more glycerol is decomposed, releasing $\mathrm{C}, \mathrm{H}$ and $\mathrm{O}$ reactive species on the surface of steel substrate. These active radicals and ionic components are accelerated by the strong electric field, generating an enhanced interstitial diffusion into the iron lattice. Consequently, $\mathrm{Fe}_{3} \mathrm{C}$ phase appears and a carburized layer is formed with the increase of discharge time. Furthermore, this hard and compact carburized layer not only improves the wear resistance of steel, but also effectively protects the steel substrate against pitting corrosion in $\mathrm{NaCl}$ aqueous solution.

\section{Conclusions}

Plasma electrolytic carburizing can form a carburized layer with tains $\alpha$-Fe and $\mathrm{Fe}_{3} \mathrm{C}$ phases and the maximum hardness is about $620 \mathrm{HV}$. The PEC treatment greatly improves wear resistance of steel. The corrosion resistance is also improved and the pitting corrosion of steel substrate is obviously suppressed.

\section{Acknowledgments}

We appreciate the help of Professor Y.L. Li in experimental tests and discussion. This research was sponsored by the National Natural Science Foundation of China (No.51071031), Beijing Natural Science Foundation (Nos.2102018 and 2122017), the Fundamental Research Funds for the Central Universities (No.211105562GK) and Specialized Research Fund for the Doctoral Program of Higher Education (No.20120003110010).

\section{References}

[1] H. Jiménez, M.H. Staia, E.S. Puchi, Surf. Coat. Technol. 120-121 (1999) $358-365$.

[2] M.F. Yan, Mater. Chem. Phys. 70 (2001) 242-244.

[3] X.Y. Li, N. Habibi, T. Bell, H. Dong, Surf. Eng. 23 (2007) 45-51.

[4] B. Suh, W. Lee, Thin Solid Films 295 (1997) 185-192.

[5] T. Christiansen, M.A.J. Somers, Surf. Eng. 21 (2005) 445-455.

[6] A.L. Yerokhin, X. Nie, A. Leyland, A. Matthews, S.J. Dowey, Surf. Coat. Technol. 122 (1999) 73-93.

[7] J. Wu, W. Xue, B. Wang, X. Jin, J. Du, Y. Li, Surf. Coat. Technol. 245 (2014) 9-15.

[8] C. Tsotsos, A.L. Yerokhin, A.D. Wilson, A. Leyland, A. Matthews, Wear 253 (2002) 986-993.

[9] B. Wang, W. Xue, J. Wu, X. Jin, M. Hua, Z. Wu, J. Alloys Compd. 578 (2013) $162-169$.

[10] X. Li, Y. Han, Electrochem. Commun. 8 (2006) 267-272.

[11] M. Tarakci, K. Korkmaz, Y. Gencer, M. Usta, Surf. Coat. Technol. 199 (2005) 205-212.

[12] F. Cavuslu, M. Usta, Appl. Surf. Sci. 257 (2011) 4014-4020.

[13] P.N. Belkin, Surf. Eng. Appl. Electrochem. 46 (2010) 558-569.

[14] J. Wu, R. Liu, W. Xue, B. Wang, X. Jin, J. Du, Appl. Surf. Sci. 316 (2014) 102-107.

[15] R.O. Hussein, X. Nie, D.O. Northwood, A. Yerokhin, A. Matthews, J. Phys. D. Appl. Phys. 43 (2010) 105203.

[16] R. Liu, J. Wu, W. Xue, Y. Qu, C. Yang, B. Wang, X. Wu, Mater. Chem. Phys. 148 (2014) 284-292.

[17] http://physics.nist.gov/PhysRefData/ASD/lines_form.html.

[18] C.J. Scheuer, R.P. Cardoso, F.I. Zanetti, T. Amaral, S.F. Brunatto, Surf. Coat Technol. 206 (2012) 5085-5090.

[19] C. Zhong, X. Tang, Y.F. Cheng, Electrochim. Acta 53 (2008) 4740-4747.

[20] F. Cao, J. Cao, Z. Zhang, J. Zhang, C. Cao, Mater. Corros. 58 (2007) 696-703.

[21] T. Chen, W. Xue, Y. Li, X. Liu, J. Du, Mater. Chem. Phys. 144 (2014) 462-469. 